\title{
Building Security Assessment Index System on Cloud Computing Platform
}

\author{
WANG Chen ${ }^{1, a^{*}}$, LEI Jing ${ }^{1, b}$ \\ ${ }^{1}$ China Academy of Electronics and Information Technology, Beijing 100041, China \\ awangchennc@sina.com, ${ }^{\mathrm{b}}$ leijanet@163.com
}

\begin{abstract}
Keywords: cloud computing, security, assessment method, assessment index.
Abstract. With the tide of Internet plus and Industry 4.0, cloud computing technology has got rapid development and extensive application while the issues of security in cloud computing platform has attracted more attentions. Initially, this paper analyzes the necessity of a comprehensive and scientific security assessment to actual cloud computing platform. In addition, it focuses on researching test method of the security performance, security risk assessment of cloud information and security assessment index system in the world, and then it establishes a scientific and complete cloud platform security assessment system. From above, it proves the effectiveness of security technology measures in cloud computing platform, with using standard specifications for security assessment of cloud computing platform. This article could provide the relative reference for security construction, security supervision and security management of cloud computing platform, and developing of cloud computing security standards.
\end{abstract}

\section{Introduction}

Cloud computing is a new emerging computing model based on the Internet, which providing high efficiency, low cost, low power computing and data service, supporting the application of all kinds of information [1]. With the development and application of cloud computing, business model and application case based on cloud has become increasingly rich, cloud computing will gradually become an important part of the national information infrastructure[2,3]. Chinese Internet data center and cloud computing security alliance research shows that most concerned problem of cloud computing is the issue of information security; What can be seen from the Gartner survey report is that, information security has been the focus of cloud computing to enterprises; cloud services platform prism events and Microsoft, Amazon, Google and other security incidents shall permit the information security problem has become the main bottleneck of development and application in cloud computing[4,5]. At present, there's no system level testing, risk assessment and the overall security solutions of the cloud security system construction in state organs, the armed forces, civilian industry. For this situation, which formulating a system-level security assessment method of cloud computing platform will have great significance to the comprehensive scientific assessment of actual cloud computation platform.

\section{Building Security Assessment Index System}

To build system-level security assessment method of cloud computing platform, first of all, establishing a scientific and complete assessment standard system through the study of cloud computing security assessment standards. Secondly, combined with various technological means, establishing assessment index and assessment process of cloud computing platform to achieve technology level assessment. Finally validating the effectiveness of security technology measures on the cloud computing platform. On the base of security assessment standard system, completing security assessment of cloud computing platform with using assessment tools. Combined with the conclusions of the assessment, providing positive solutions of defects and loopholes of security system in the target cloud computing platform. 


\section{Design Ideas}

At present, the mainstream of information system assessment criteria is both technical and management, such as the basic requirements of information system classified protection. Cloud computing platform is a special information system, and its assessment index system can be divided into two parts of the technology and management refers to the basic requirements of information system classified protection [6,7].

According to the special characteristics of cloud computing, "Security capability requirements of cloud computing services" put forward ten kinds of security requirements to cloud service providers, which are universal. Therefore, the assessment index system of the specific indexes, in particular, technical indexes can refer to the "Security capability requirements of cloud computing services".

To sum up, this article will refer to the basic requirements of information system classified protection and the "Security capability requirements of cloud computing services", the assessment index system for stratification, and set the corresponding technical indexes and management indexes.

\section{Security Assessment Index System}

As shown in Figure 1, the entire index system has a total of 4 layers. According to the basic requirements of information system classified protection, first-level indexes contain two categories: technical requirements and management requirements.

The technical requirements of second-level indexes can mainly be classified in accordance with the cloud computing service model (IaaS, PaaS, SaaS), as well as common security. Third-level index can be got through decomposition of the connotation and characteristics of second-level indexes, for example, second-level index IaaS include third-level index of physical and environmental security, network security, host security, virtualization security, storage security; Second-level index PAAS includes third-level index of operation security, interface security and system security; Second-level index SaaS includes third-level index of application security, information security; Second-level index common security includes third-level index of data security, backup recovery and data migration. Fourth-level indexes can be got through division of the third-level indexes, and also can be directly involved in the test part of the index, here is no longer listed.

The second-level indexes of management requirements are mainly in accordance with which security management system, security management agencies, personnel security management and other security requirements in basic requirements of information system classified protection for classification. The third-level indexes are classified according to the basic requirements of information system classified protection and security capability requirements of cloud computing services, such as risk assessment and continuous monitoring, maintenance, access control and other security requirements. The fourth-level indexes are the specific security requirements contained in the third-level indexes. It is also no longer listed here.

Fig.1 Cloud computing security assessment index system (3 layer structure)

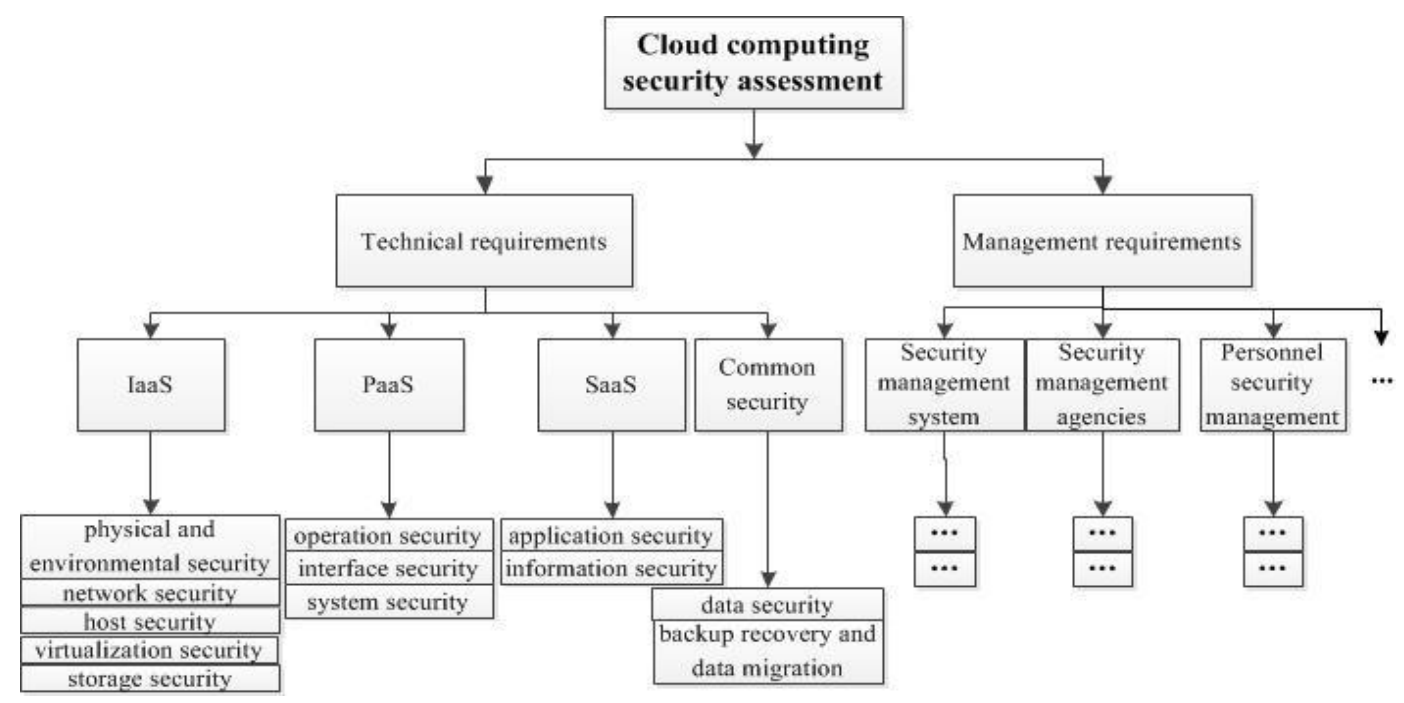




\section{The Method of Security Assessment}

Based on the weight of the security assessment index of the target cloud computing system, the score of the fourth level security assessment index is weighted average, and then the score of the third level security assessment index is obtained. And so on, finally get the score of first level security assessment index, as well as score of target cloud computing system.

By monitoring the network interface of the target cloud computing system, the source data of the target cloud computing system can be evaluated. According to cloud computing system source data, the score of fourth-level security assessment index in cloud computing system security assessment index can be got. The type of source data in assessed target cloud computing system includes Boolean, integer and decimal. The boolean type numerical direct conversion as a score of 0 or 1 , other types of data, according to the preset cloud computing system security assessment index statistics interval of linear or nonlinear mapping to obtain the score between 0 and 1. According to the mapping relationship between the source data and the fourth level security assessment index, the score of the fourth level security assessment index is calculated.

If the four level security assessment indexes are the default key indexes, the four level security assessment index score for the four level security assessment index related to the source data in the lowest score; and if the four level security assessment index related to the source data are in the same grade, the fourth level security assessment index score for the four level security assessment index related data source score of arithmetic mean value; and if the four level security assessment index related to the source data of important level is not the same, according to the preset weights of the four level security assessment indexes related to the source data value weighted average algorithm to calculate the security assessment index score.

For example as follows:

Assuming a total of 10 fourth- level security assessment indexes $\mathrm{P}_{0}-\mathrm{P}_{9}$, the corresponding weights are all the same of 1 . The type of source data $\beta_{7}-\beta_{9}$ of index $P_{7}-P_{9}$ is boolean, and $\beta_{7}$ and $\beta_{8}$ to,$\beta_{9}$ to 0 ; The source data type of $\mathrm{P}_{0}-\mathrm{P}_{6}$ is non-Boolean, which $\mathrm{P}_{0}$ and $\mathrm{P}_{3}$ as the key indexes, $\mathrm{P}_{4}-\mathrm{P}_{6}$ as non-key indexes, the seven indexes corresponded to three source data $\beta_{\mathrm{X} 0}, \beta_{\mathrm{X} 1}, \beta_{\mathrm{X} 2}$, specific score are shown in Table 1. At the same time the important level of the second-level indexes is set the same, the third-level indexes are also the same level of importance, so the system score $\mathrm{S}$ can be evaluated by the fourth level of security assessment indexes weighted average.

Table 1 the score of non-Boolean source data

\begin{tabular}{|c|c|}
\hline Index & Score \\
\hline $\mathrm{P}_{0}$ & $\beta_{00}=0.3, \beta_{01}=0.6, \beta_{02}=0.8$ \\
\hline $\mathrm{P}_{1}$ & $\beta_{10}=0.8, \beta_{11}=0.5, \beta_{12}=0.9$ \\
\hline $\mathrm{P}_{2}$ & $\beta_{20}=0.7, \beta_{21}=0.7, \quad \beta_{22}=0.7$ \\
\hline $\mathrm{P}_{3}$ & $\beta_{30}=0.9, \beta_{31}=0.9, \quad \beta_{32}=0.8$ \\
\hline $\mathrm{P}_{4}$ & $\beta_{40}=0.6, \beta_{41}=0.7, \beta_{42}=0.8$ \\
\hline $\mathrm{P}_{5}$ & $\beta_{50}=0.3, \beta_{51}=0.9, \beta_{52}=0.9$ \\
\hline $\mathrm{P}_{6}$ & $\beta_{60}=0.8, \beta_{61}=0.8, \beta_{62}=0.8$ \\
\hline
\end{tabular}

$$
\begin{aligned}
& S=A_{0} * \beta_{0}+A_{1} * \beta_{1}+\ldots+A_{9} * \beta_{9} . \\
& \beta_{X}=\operatorname{Min}\left\{\beta_{X 0}, \beta_{X 1}, \beta_{X 2}\right\}(\operatorname{Min}\{\} \text { is minimum operation, } X=0,1,2,3) . \\
& \beta_{Y}=\left(\beta_{Y 0}+\beta_{Y 1}+\beta_{Y 2}\right) / 3(Y=4,5,6) .
\end{aligned}
$$




$$
\begin{aligned}
& \beta_{7}=\beta_{8}=1, \beta_{9}=0 . \\
& \text { From (1) to (4): } \\
& S=1 * 0.3+1 * 0.5+1 * 0.7+1 * 0.8+1 *(0.6+0.7+0.8) / 3+1 *(0.3+0.9+0.9) / 3+ \\
1 * & (0.8+0.8+0.8) / 3+1 * 1+1 * 1+1 * 0=6.5
\end{aligned}
$$

The security assessment score is 6.5 .

\section{Conclusion}

With the rapid development of cloud computing, big data and other industries, security risks which brought by the lack of cloud security standards, cloud security assessment solutions are increasingly highlighted. On the domestic and foreign cloud computing test standards, technical standards, and on the basis, the cloud computing platform designed for the characteristics of established a can improve the cloud computing platform security assessment standard system, according to the standard assessment, which is based on cloud computing platform security and performance testing results, from the point of view of system level and implementation of security assessment of automation. Through the security assessment methods, assessment and detection of cloud computing platform design and realization is in accordance with the state of cloud computing in product standards related to security requirements, enhance the independent high security cloud computing platform security, a strong push forward independent high security cloud computing platform construction process.

\section{References}

[1] J. van der Geer, J.A.J. Hanraads, R.A. Lupton, The art of writing a scientific article, J. Sci. Commun. 163 (2000) 51-59.

[1] Y.L Yan, Z.Y Huang, H Zhang, Design and technology research of data center network architecture in the background of cloud computing, mobile communication. 20 (2013):80-86.

[2]J Song, L Zhu, Design and implementation of massive data processing platform based on cloud computing, Telecommunication engineering. 52(2012)566-570.

[3]X.M Yang, H.F Luo, Technical analysis of information system security risk assessment, Computer application. 28(2008)1920-1923.

[5] D.G Feng, Y Zhang, Y.Q Zhang, Review of information security risk assessment, Journal of communication. 25(2004)10-18.

[6]X.Z Wang, Y Ma, Information security risk assessment in cloud computing, Computer security. 9 (2014)37-40.

[7]Y.C Zhou, X.D Zuo, Analysis on the national standard of "cloud computing service security capability requirement", Standardization research. 8 (2014)58-61. 